\title{
Arrhythmogenic right ventricular dysplasia. An illustrated review highlighting developments in the diagnosis and management of this potentially fatal condition
}

\author{
N G Fisher, T J Gilbert
}

\begin{abstract}
Arrhythmogenic right ventricular dysplasia is an inherited, progressive condition. Characterised by fatty infiltration of the right ventricle, it frequently results in life threatening cardiac arrhythmias, and is one of the important causes of sudden cardiac death in the young. There are characteristic electrocardiographic and echocardiographic features that all physicians need to be aware of if we are to reduce these occurrences of premature death. Diagnosis with magnetic resonance imaging is discussed along with current treatment options.
\end{abstract}

(Postgrad Med f 2000;76:395-398)

Keywords: arrhythmogenic right ventricular dysplasia

Arrhythmogenic right ventricular dysplasia (ARVD) is an important cause of sudden death in young people. Awareness of the condition is essential so that it may be recognised as soon as possible. This may avoid postmortem diagnosis and allow prompt screening of relatives. The prevalence of this condition is one in 5000 and in $30 \%-40 \%$ of patients it is inherited as an autosomal dominant trait, with incomplete penetrance and variable expression. ${ }^{1-4}$ Four loci have been mapped, but no gene has been identified as yet. ${ }^{5}$ Clinical descriptions of ARVD first appeared in $1961,{ }^{6}$ but it was not until 1978 that it was first given this title. ${ }^{7}$

\section{Presentation}

Individuals, more often male, may present between the ages of 7-40 years with the youngest recorded case being 4 years. Eighty per cent of patients are detected before their 40th birthday. ${ }^{89}$ The classic presentation is with symptomatic sustained ventricular tachycardia, the electrocardiogram (ECG) showing a left bundle branch block pattern. Less common presentations are as a supraventricular tachycardia, multiple ventricular ectopics, ${ }^{7} 11{ }^{11}$ or merely cardiomegaly on chest radiography. ${ }^{9}$

Typical symptoms are fatigue on minimal exertion and syncope; this reflects the high incidence of the arrhythmia during exercise. Unfortunately a proportion will also present as sudden cardiac death. ${ }^{8}{ }^{12}$

Thiene et al discovered that postmortem examination showed evidence of ARVD in $20 \%$ of sudden deaths in people under the age of $35 .^{13}$

\section{Aetiology and pathology}

ARVD is characterised by the deposition of adipose tissue and the development of fibrosis within the right ventricular myocardium ${ }^{14}$ a feature rarely found in the left ventricle. ${ }^{15-18}$ Typically this process will commence in the epicardium and progress towards the endocardium.

The aetiology is unknown but Thiene et al have suggested that an inflammatory or autoimmune process may be involved. ${ }^{19}$

\section{Case report}

In 1978 a 25 year old male athlete was investigated for epilepsy having lost consciousness while running. The exercise itself was not thought to be influential, as he regularly ran in excess of five miles daily. There was a history of palpitation while running but investigations were all normal.

Four years later he presented with extreme nausea and malaise during exercise. An ECG recorded during one of these episodes was consistent with atrial tachycardia. Investigations including echocardiography, radionucleotide angiography, and cardiac catheterisation were normal. During electrophysiological studies only a self terminating atrial tachycardia occurred. The patient was discharged with no treatment. He remained under regular review. Of importance, however, was his 12 lead ECG in sinus rhythm that showed inverted $\mathrm{T}$ waves in the precordial leads (fig 1).

Ten years later he was admitted with a symptomatic broad complex tachycardia that required DC cardioversion. Again all of the above investigations were normal apart from his ECG and electrophysiological studies, which this time demonstrated easily induced ventricular tachycardia with the focus in the right ventricle. Over the next few years a variety of medications were used until amiodarone was found to be the best compromise between arrhythmia control and intolerable drug side effects.

In 1985 the diagnosis of ARVD was made supported by radionucleotide angiography demonstrating a dilated akinetic right ventricle with an ejection fraction of $15 \%$ and electrophysiological studies showing easily inducible sustained ventricular tachycardia. The ventricular tachycardia showed typical left bundle branch block morphology with left axis deviation (fig 2).

In 1994 the patient's younger brother aged 37 years lost consciousness during a karate les-
Submitted 12 July 1999 Accepted 27 October 1999 


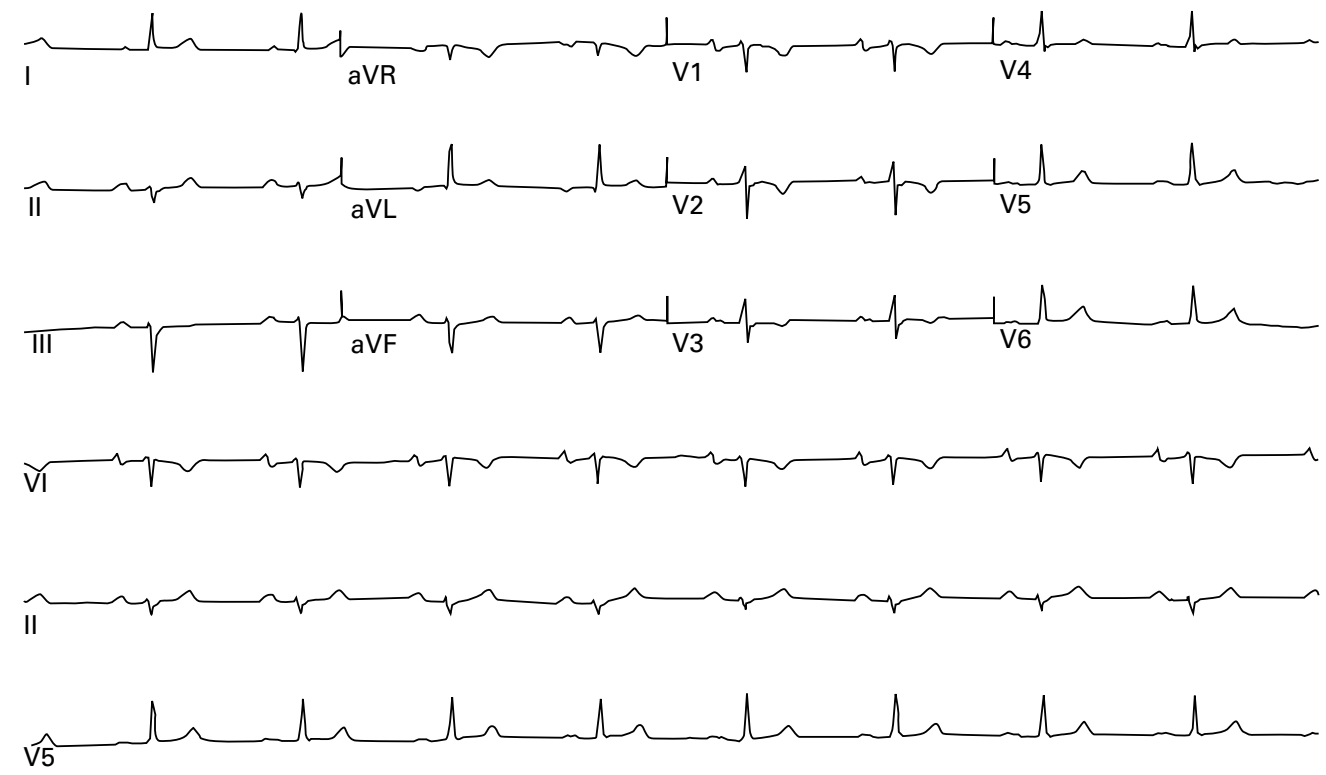

Figure 1 ECG in sinus rhythm showing inverted $T$ waves in the precordial leads.

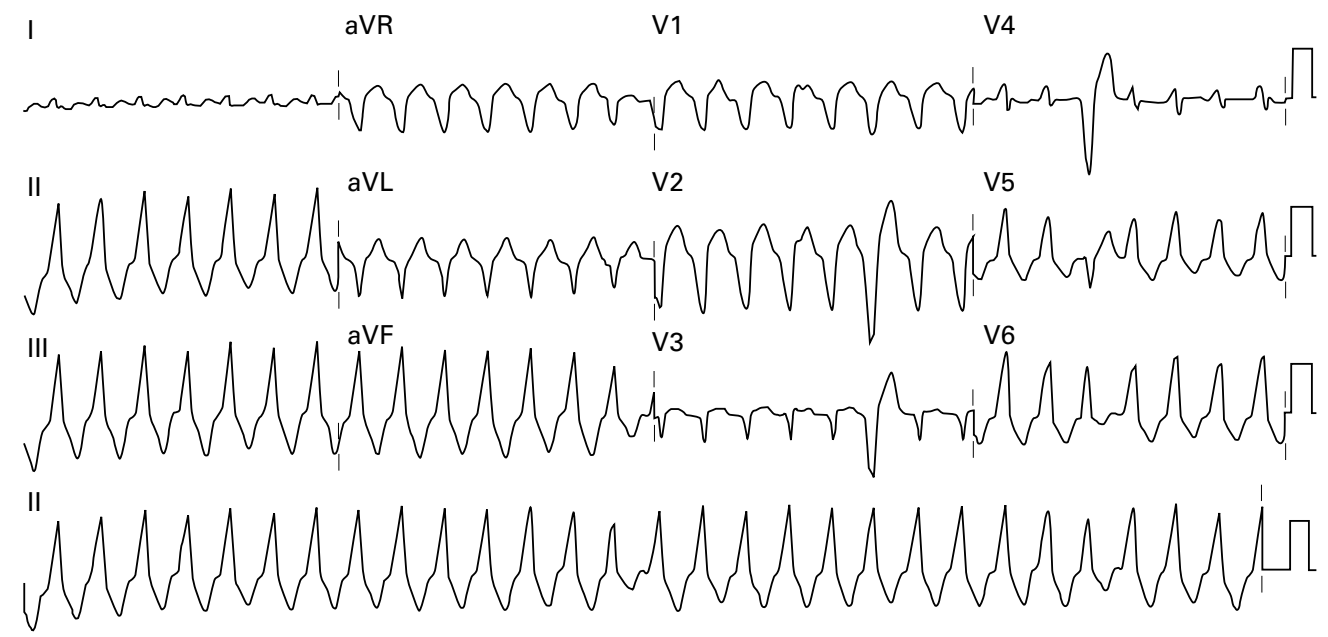

Figure 2 Ventricular tachycardia showing typical left bundle branch block morphology with left axis deviation.

son. His 12 lead ECG showed inverted T waves in the precordial leads and multiple ventricular ectopics. Echocardiography and radionucleotide angiography supported the diagnosis of ARVD. Electrophysiological studies including a ventricular tachycardia stimulation test was normal. Three years later he died suddenly while sitting at home. Postmortem examination confirmed abnormalities consistent with ARVD. The patient's daughter has been screened. Her ECG and echocardiogram are also consistent with ARVD.

After being asymptomatic for 12 years the patient then suffered increasingly frequent and prolonged ventricular tachycardia induced by exertion. This was reliably induced on the treadmill. Additional medical treatment $(\beta-$ blockers) induced Mobitz type II heart block. Therefore, taking these factors and his brother's history into account, a dual chamber pacing rate responsive automatic cardioverter defibrillator was implanted.

Despite the introduction of a small amount of $\beta$-blocker he continued to experience frequent episodes of ventricular tachycardia, which the device detected and treated appropriately. He was intolerant of higher doses of $\beta$-blocker. Therefore, a radiofrequency catheter ablation was carried out to one of two ventricular tachycardia foci in the right ventricle. Although initially successful at controlling the slowest foci of ventricular tachycardia, he has experienced a recurrence of symptoms, although these are tolerably well controlled with the combination of amiodarone and a tiny dose of $\beta$-blockade.

To date this latest treatment has provided good symptomatic relief but our knowledge of the disease tells us that this history is probably not yet complete.

\section{Detection}

ELECTROCARDIOGRAM

The important features on a standard 12 lead ECG are $T$ wave inversion in the precordial leads (which may of course be a normal variant) and prolongation of the QT interval greater than $110 \mathrm{~ms}$ (see box 1). The latter is $100 \%$ specific but only seen in a third of patients. ${ }^{20}$ The cause of this QT interval 


\section{Box 1: ECG features of ARVD \\ - T wave inversion in the precordial leads. \\ - QT interval greater than $110 \mathrm{~ms}$. \\ - Ventricular ectopics in excess of 1000 per day. \\ - Ventricular tachycardia which has a left bundle branch block pattern.}

increase is thought to be delayed right ventricular activation, which produces a small irregularity after the QRS complex called an epsilon wave which is rarely seen on a standard ECG can be detected in about a third of patients using signal averaged techniques. ${ }^{22}$ Ventricular ectopics, although not abnormal in themselves, tend to occur in excess of 1000 per day. $^{23}$

Exercise testing can often provoke the arrhythmia resulting in ventricular tachycardia which has a left bundle branch block pattern. ${ }^{24}$

\section{ECHOCARDIOGRAPHY}

Features associated with ARVD are shown in box $2 .{ }^{1025}{ }^{26}$ In addition calculations of the ratio of right and left ventricular end diastolic diameters appear to give values of sensitivity of $86 \%$ and specificity of $93 \% .^{27} 28$

\section{ENDOCARDIAL BIOPSY}

Although the histological abnormalities are predominantly in the right ventricular free wall, biopsies are frequently taken from the septal area to reduce the risk of perforation. ${ }^{29}$ This obviously reduces the chances of obtaining affected tissue and it must be remembered that a negative biopsy specimen does not exclude the condition.

MAGNETIC RESONANCE IMAGING (MRI) AND RIGHT VENTRICULAR ANGIOGRAPHY

Until recently right ventricular angiography was considered to be the optimal imaging modality for detecting ARVD. However, with cardiac gating and better resolution MRI may well begin to supersede this investigation. Typical features include isolated areas of dyskinesia, transverse hypertrophic trabeculae separated by deep fissures, and an increase in end diastolic volume..$^{30-32}$

MRI has the ability not only to describe right ventricular morphology but also to highlight areas of myocardial fat distribution. ${ }^{33}{ }^{34}$ Midiri et al have discovered that these areas of adipose tissue within the myocardium correspond with the focus of the arrhythmias. ${ }^{35}$ McKenna et al have defined criteria to aid in the diagnosis of ARVD. ${ }^{36}$

\section{Treatment}

DRUGS

Amiodarone and $\beta$-blockers can both be effective, in addition there appears to be a synergistic affect when they are used together. However, sotalol has been shown by Wichter et al to be the most reliable treatment. ${ }^{37}$
Box 2: Echocardiography features of ARVD

- Right ventricular dilation.

- Bulging of right ventricle during diastole.

- Dyskinesia of inferobasal free wall during systole.

- Dyskinesia of the apex.

- Exaggerated trabecular pattern within right ventricle.

- Structural abnormalities of the moderator band.

Unfortunately ARVD is a progressive disorder and patients often become resistant to one or more medications requiring more invasive intervention.

\section{IMPLANTABLE DEFIBRILLATORS}

Implantable defibrillators are now effective treatment for ventricular cardiac arrhythmias. ${ }^{38}$ As illustrated in our case report ARVD frequently becomes resistant to drug treatment and therefore use of implantable defibrillators in this condition seems appropriate. However, it is important to achieve relatively reliable control of the arrhythmias before implantation as this avoids repeated shocks being delivered by the device, which can be very distressing for the patient.

RADIOFREQUENCY CATHETER ABLATION

Advances in cardiac electrophysiology have enabled cardiologists to map and ablate the focus of the arrhythmias with success rates of up to $70 \%$. In addition, patients in whom the procedure is unsuccessful in itself often find that drug therapy is subsequently more effective. As the disease progresses patients run a high risk of developing a second focus. ${ }^{39} 40$

SURGERY

Surgical total or partial isolation of the right ventricular free wall appears to have had some success. Even if ventricular tachycardia does occur in the right ventricle it is unable to propagate into the left side. The major postoperative complication is right ventricular failure and long term data on these patients are not yet available. ${ }^{41}{ }^{42}$ Cardiac transplantation is also a recognised treatment for this condition but carries with it a significant amount of mortality and morbidity and is therefore seen as a last resort. $^{43}$

\section{Conclusion}

ARVD is an important cause of sudden death in young people. The case described here spans the time period during which ARVD was being defined and the delay in diagnosis reflects this. With our current knowledge it is clear that the patient was demonstrating classical symptoms and signs from the outset. The death of his brother and birth of his daughter who also has the classical ECG appearances of AVRD, highlight the genetic importance of the condition. 
Our case illustrates how the disease can progress and become unstable, thus requiring a flexible approach to treatment.

1 Laurent M, Descaves C, Biron Y, et al. Familial form of arrhythmogenic right ventricular dysplasia. Am Heart $\mathcal{f}$ 1987;113:827-9.

2 Nava A, Thiene G, Canciani B. Familial occurrence of right ventricular dysplasia. A study involving nine families. $\mathcal{F} \mathrm{Am}$ Coll Cardiol 1988;12:1222-8.

3 Ruder MA, Winston SA, Davis JC, et al. Arrhythmogenic right ventricular dysplasia in a family. Am $\mathcal{F}$ Cardiol 1985;56: 799-800.

4 Buja G, Nava A, Daliento L, et al. Right ventricular cardiomyopathy in identical and non-identical young twins. $A m$

5 Ahmad F, Li D, Karibe A, et al. Localization of a gene responsible for arrhythmogenic right ventricular dysplasia to chromosome 3p23. Circulation 1998;98:2791-6.

6 Dalla Volta S, Battagiia G, Zerbini E. Auricularisation of the right ventricular pressure curve. Am Heart f 1961;61:25-33.

7 Frank R, Fontain G, Vedel J, et al. Electocardiologe de quatre cas de dysplasie ventriculaire droite arythmoge. Arch Mal Coeur 1978;71:963-72.

8 Dalla Volta S. Arrhythmogenic cardiomyopathy of the right ventricle. Thoughts in aetiology. Eur Heart f 1989;10(suppl D):2-6.

9 Kullo IJ, Edwards WD, Seward JB. Right ventricular dysplasia: the Mayo Clinic experience. Mayo Clin Proc 1995;70:541-8.

10 Marcus F, Fontain G, Guiroudon G, et al. Right ventricular dysplasia: a report of 24 adult cases. Circulation 1982;65: 384-99.

11 Vikhert A, Tsiplenkova V, Cherpachoenko N. Alcoholic cardiomyopathy and sudden death. $7 \mathrm{Am}$ Coll Cardiol diomyopathy and

12 Wight JN, Salem D. Sudden death and the "athletes heart" Arch Intern Med 1995;155:1473-80.

13 Thiene G, Nava A, Corrado D, et al. Right ventricular cardiomyopathy and sudden death in young people. $N$ Engl $\mathcal{F}$ Med 1998;318:129-33

14 Lobbo FV, Heggtveit HA, Butany J, et al. Right ventricular dysplasia: morphological findings in 13 cases. Can 7 Cardiol 1992;8:261-8

15 Manyari D, Klein F, Fulamhusein S. Arrhythmogenic right ventricular dysplasia: a generalised cardiomyopathy? Circulation 1993;68:251-7.

16 Pinamonti B, Singara G, Di Lenerda A, et al. Left ventricular involvement in right ventricular cardiomyopathy. Postgrad Med f 1992;68(suppl 1):S36-9.

17 Blomstrom-Lundquist C, Sabel KG, Olsson SB. A long term follow up of fifteen patients with arrhythmogenic right term follow up of fifteen patients with arrhythmog.
ventricular dysplasia. Br Heart 7 1987;58:477-88.

18 Gallo P, d'Amati G, Pellicia F. Pathological evidence of right ventricular involvement in arrhythmogenic right ventricular ventricular involvement in arrhythmogenic righ
cardiomyopathy. Hum Pathol 1992;23:948-52.

19 Thiene G, Corrado D, Nava A, et al. Right ventricular cardiomyopathy: is there evidence of an inflammatory aetiology? Eur Heart f 1991;12:22-5.

20 Fontain G, Umemura J, Di Donna P, et al. La duree des complexes QRS dans la dysplasia ventriculaire arrhythmogene. Un nouveau marqueur diagnostique non invasif. Ann Cardiol Angeiol (Paris) 1993;42:399-405.

21 Nava A, Canciani D, Buja G, et al. Electrocardiographic study of negative T-waves on precordial leads and arrhythmogenic right ventricular dysplasia: relationship with arrhythmogenic right ventricular dysplitationship with

22 Fontain G, Frank R, Gallais-Hammono F, et al. Electrocardiograie des potentiels tardifs du syndrome de postexcitation. Arch Mal Coeur 1978;71:845-56.

23 Fontain G, Frank R, Tsezana R, et al. Electrophysiologic characteristics in arrhythmogenic right ventricular dysplasia
and dilated cardiomyopathies. In: Aubert AE, Ector H, and dilated cardiomyopathies. In: Aubert AE, Ector H,
Stroobant R, eds. Cardiac pacing and electrophysiology. The Stroobant R, eds. Cardiac pacing and electrophysiolo
Netherlands: Kluwer Academic Publishers, 1994.
24 Daubert C, Vauthier M, Carre F, et al. Influence of exercise and sport activity on functional symptoms in ventricular and sport activity on functional symptoms in ventricular (abstract). $\mathcal{F}$ Am Coll Cardiol 1994;23:34A.

25 Scognamiglio R, Fasoli G, Nava A, et al. Two-dimensional echocardiographic features in patients with spontaneous right ventricular tachycardia without apparent heart disease. fCardiovasc Ultrason 1987;6:113-17.

26 Baron A, Nanda N, Falkoff M, et al. Two-dimensional echocardiographic detection of arrhythmogenic right ventricular dysplasia. Am Heart f 1982;103:1066-7.

27 Manyari DE, Duff HJ, Kostuk WJ, et al. Usefulness of noninvasive studies for diagnosis of right ventricular dysplasia. Am f Cardiol 1986;57:1147-53.

28 Gaffney FA, Nicod P, Lin JC, et al. Noninvasive recognition of the parchment right ventricle (Uhl's anomaly arrhythmogenic right ventricular dysplasia) syndrome. Clin Cardiol 1983;6:235-42.

29 Strain J. Adipose dysplasia in the right ventricle: is endomyocardial biopsy useful? Eur Heart $\mathcal{F}$ 1989;10(suppl D): $89-91$.

30 Drobinsky G, Verdiere C, Fontaine G, et al. Diagnostic angiographique des dysplasies ventriculaires droites. Arch Mal Coeur 1985;78:544-51.

31 Robertson H, Brady G, German L, et al. Comparison of two-dimensional echocardiographic and angiographic findings in arrhythmogenic right ventricular dysplasia. $\mathrm{Am} \mathcal{F}$ ings in arrhythmogenic
Cardiol 1985;55:1506-8.

32 Rossi P, Massumi A, Gillete P, et al. Arrhythmogenic right ventricular dysplasia: clinical features diagnostic techniques and current management. Am Heart f 1982;103:415-20.

33 Casalo GC, Poggese L, Boddi M, et al. ECG-gated magnetic resonance imaging and right ventricular dysplasia. Am Heart f 1989;113:1245-8.

34 Klersy C, Raisaro A, Salerno J, et al. Arrythmogenic right and left ventricular disease: evaluation by computed tomography and nuclear magnetic resonance imaging. Eur Heart 7 1989;10(suppl D):84-8.

35 Midiri M, Fiazzo M, Brancato M, et al. Arrythmogenic right ventricular dysplasia; MR features. European Radiology

36 McKennna WJ, Thiene G, Nava A, et al. Diagnosis of arrhythmogenic right ventricular dysplasia/cardiomyopathy. Task force of the Working Group on Myocardial and Pericardial Disease of the European Society of Cardiology and the Scientific Council on Cardiomyopathies of the International Society and Federation of Cardiology. $\mathrm{Br}$ Heart $\mathcal{F}$ 1994; $71: 215-18$.

37 Wichter T, Borgreffe M, Haverkamp W, et al. Efficacy of antiarrhythmic drugs in patients with arrhythmogenic right ventricular disease. Circulation 1992;86:29-37.

38 Anti-arrhythmics Versus Implantable Defibrillators (AVID) Investigators. A comparison of antiarrhythmic-drug therapy with implantable defibrillators in patients resuscitated from near-fatal ventricular arrhythmias. $N$ Engl f Med 1997;337: near-fatal

39 Fontain G, Frank R, Rougier I, et al. Electrode catheter ablation of resistant ventricular tachycardia in right ventricular dysplasia: experience of 13 patients with a mean follow up of 45 months. Eur Heart $\mathcal{f}$ 1989;10(suppl D): $82-3$

40 Leclercq G, Chouty F, Cauchemez B, et al. Results of electrical fulguration in arrhythmogenic right ventricular disease. Am f Cardiol 1988;62:220-4.

41 Guiraudon G, Klein GJ, Gulamhusein SS. Total disconnection of the right ventricular free wall: surgical treatment of right ventricular tachycardia associated with right ventricular dysplasia. Circulation 1983;67:463-70.

42 McLay JS, Norris A, Campbell RW, et al. Arrhythmogenic right ventricular dysplasia: an uncommon cause of ventricular tachycardia in young and old? Br Heart $\mathcal{f} 1993 ; 69: 158-$ lar tach.

43 Oteo JF, Alonso-Pulpon L, Cavero MA, et al. Right ventricular arrhythmogenic dysplasia. The role of heart transplantation in its management. Rev Esp Cardiol 1994;47: 